\title{
Fridays For Future Meets Citizen Science Resilience and Digital Protests in Times of Covid-19
}

\author{
Witold Mucha \\ Institute of Social Sciences | Heinrich-Heine University Düsseldorf | witold.mucha@hhu.de \\ Anna Soßdorf \\ Institute of Social Sciences | Heinrich-Heine University Düsseldorf | anna.sossdorf@hhu.de \\ Laura Ferschinger \\ Institute of Social Sciences | Heinrich-Heine University Düsseldorf | ferschinger@phil.hhu.de
}

\section{Viktor Burgi}

Institute of Social Sciences | Heinrich-Heine University Düsseldorf | burgi@phil.hhu.de

\begin{abstract}
Based on a Citizen Science (CS) project which brings together scholars and Fridays For Future (FFF) activists, the article attempts to understand what effects the Covid-19 pandemic has on the movement in terms of communication, organization and mobilization. The methodological CS rationale is that the activists in their role as citizen scientists are better equipped to address the relevant questions and methods than traditional scholars. The paper presents findings of a national survey designed in cooperation with FFF activists on how the movement responded to the challenges posed by Covid-19. The analysis shows that FFF has been strikingly resilient to the pandemic situation given its digital backbone as an organization. Digital and physical protests were organized and the internal and external communication was kept afloat.
\end{abstract}

Keywords: Fridays for Future; climate strike; citizen science; Covid-19; pandemic; knowledge production; resilience

\section{Zusammenfassung}

Der Artikel untersucht vor dem Hintergrund eines Citizen-Science-Projekts (CS), das Wissenschaftler*innen mit Fridays-For-Future-Aktivist*innen (FFF) zusammenbringt, welche Effekte die Covid-19 Pandemie auf die Kommunikation, Organisation und Mobilisierung der Bewegung hat. Die Kooperation mit den Aktivist*innen liegt in dem CSGedanken begründet, dass Bürgerwissenschaftler*innen besser in der Lage sind, die relevanten Forschungsfragen und -methoden zu identifizieren als etablierte Forscher*innen. Der Artikel präsentiert Ergebnisse einer in Zusammenarbeit mit den Aktivist*innen entwickelten Umfrage zu den Reaktionen von FFF auf die Pandemie. Die Analyse zeigt, dass FFF eine erstaunliche Resilienz gegenüber den Herausforderungen aufweist, die sich auf das digitale Rückgrat der Organisation zurückführen lässt. Digitaler und physischer Protest wurde organisiert und die interne und externe Kommunikation ungehindert fortgeführt.

Schlagwörter: Fridays for Future; Klimastreik; Bürgerforschung; Covid-19; Pandemie; Wissensproduktion; Resilienz 


\section{Introduction ${ }^{1}$}

The Fridays For Future (FFF) climate protests mobilized more than four million people around the globe in September 2019. In contrast to previous youth movements, FFF has been strikingly successful in drawing global attention (de Moor et al. 2020). Thus far, most studies have dealt with the activists' reliance on social media and peer networks, their limited commitment to traditional organizations, or their socioeconomic characteristics such as the movement's strong female presence (Anzlinger/Bovermann 2019; de Moor et al. 2020; Neuber/Gardner 2020; Rucht 2019; Sommer et al. 2019). This research has shed light on relevant features of the movement which help to understand their success in mobilizing supporters and activists. However, most findings have remained on the macro level of the phenomenon. For instance, there is a lack of knowledge on the various means of mobilizing protestors on local ground. Considering the 650 different local groups in Germany alone, more in-depth analyses are palpable. From an organizational sociological perspective, the need for micro and meso level studies is paramount especially when taking into account the challenges Covid-19 has brought about to movements such as FFF that rely on publicly visible mass mobilization.

Based on a Citizen Science (CS) project at the Heinrich-Heine University of Düsseldorf, Germany, which brings together scholars and ten local FFF activists, this paper addresses the research gaps by responding to the question: What effects does the Covid-19 pandemic have on the movement in terms of communication, organization and mobilization? The research project differs from previous methodologies by making the activists part of the knowledge producing process. The CS rationale behind this method is that the activists in their role as citizen scientists are better equipped to address the relevant questions and apply adequate methods than traditional scholars. More importantly, the ten core activists differ from the other protest participants that take part in the Friday demonstrations, as they engage in activities beyond mere protesting. Having the core activists on board therefore allows for a much more FFF-contextual research direction as well as a more exclusive perspective and access to the field - a unique asset most studies in the literature do not hold.

Against this backdrop, the article presents findings of a national survey designed in cooperation with FFF activists on how the movement responded to the manifold challenges posed by Covid-19. The analysis shows that FFF has been strikingly resilient to the pandemic situation given its digital backbone as an organization: First, messenger services are and have been major tools used to organize, communicate and mobilize even before the outbreak of the pandemic. Second, the lack of personal communication has been compensated by videoconferencing. Third, physical

1 We would like to thank the anonymous reviewers and our colleague Viviana Warnken for their very useful comments on earlier drafts of this article. 
forms of protest such as Friday demonstrations, chalk and placard activities have been replaced by online equivalents such as online strikes or other social media actions.

The article is divided into five parts. Following the introduction, FFF as a social movement will be presented. Thereafter the goals of the research project will be introduced. Based on this, the design and the findings of a national survey on the communication, organization and mobilization on FFF in light of the pandemic will be presented. At last, the implications for future research will be discussed from a CS perspective.

\section{Fridays For Future - a social movement in times of a pandemic}

Up to the onset of the Covid-19 pandemic in the early spring of 2020, the Fridays For Future movement had gained great momentum with its first climate strikes, beginning in September of 2018, and thereafter mobilizing 25,000 participants in January 2019, 300,000 in March, 1.4 million in September and 630,000 in November, and that alone in Germany (Anzlinger/Bovermann 2019; Neuber/Gardner 2020; Sommer et al. 2019). During this time the FFF protesters aroused great public interest and media response as they were a unique group of school-aged youth, over proportionally female, and relatively well-educated, putting weekly pressure on authorities demanding action be taken against climate change. This group of activists differed from the traditional protester image of male, adult and well-educated (de Moor et al. 2020; Neuber/Gardner 2020). During the protest events of 2019 however, surveys of the protesters reveal a change in the movement's base of young participants and a transition of the FFF movement from a youth movement towards a comprehensive social movement in German society (Neuber/Gardner 2020). Other distinctive features of the FFF movement are its strong reliance on social media and peer networks (Wahlström et al. 2019). To communicate, local FFF groups used to meet personally and use instant messengers such as WhatsApp and Telegram. These tools are not only means of communication but are also use in their decision-making processes and for voting purposes (Sommer et al. 2019). FFF mobilizes the public via social media and personal contact (Neuber/Gardner 2020). Further, the movement is organized informally and has limited ties to existing environmental organizations (Wahlström et al. 2019). From the perspective of social scientists FFF therefore can be classified as a social movement as it meets all of the formal criteria of a social movement: It is an informal network which emerged outside of established institutions, its members work towards a common political goal, share common beliefs and a collective identity and take collective action by using different forms of protest (della Porta/Diani 1999). Furthermore, FFF is not solely a social movement taking offline action to bring about social change but 
a movement that enhances its actions with various digital forms as it heavily relies on social media and online services to communicate, mobilize and organize itself (Boulianne/Lalancette/Ilkiw 2020; Neuber/Gardner 2020; Sommer et al. 2019).

FFF is a decentralized organization consisting of international, national, and local groups. In Germany more than 650 local groups have been established (Fridays For Future Germany 2020a). In general, actions are planned and carried out by activists of these local groups. Each local group has teams that deal with the organization of protest marches and the finances. They elect two to four delegates to participate in the nationwide cooperation of the FFF movement. These delegates take part in weekly conference calls and pass information onto their members. To allow for nationwide collaboration, activists come together in about 20 issue-specific working groups which deal with finances, campaigns, political demands, media relations etc. There is no executive board nor spokesperson, however prominent activists such as Greta Thunberg or Luisa Neubauer in Germany play a central role in representing the movement. This has led to a sort of personality cult which has been a topic of critical discussion within the movement (Sommer et al. 2019). At the same time these improvised, unfixed organizational structures attract young people as it stands in sharp contrast to established associations and parties (Sommer et al. 2019). FFF is financed mainly by donations and the authorized sale of bracelets.

The Covid-19 pandemic in March 2020 and the imposed assembly restrictions and social distancing have prevented further protest marches from taking place. Personal group meetings are difficult, if not impossible. Nevertheless, FFF found alternative ways to express their demands by shifting their protests online and performing offline actions such as the spreading of posters in front of the German Bundestag (Süddeutsche Zeitung 2020a; Süddeutsche Zeitung 2020b). Despite the fact that public focus has seemingly shifted from concerns of climate change to the circumstances brought about by the Covid-19 pandemic, FFF took its protest back onto the streets in the fall of 2020 (Zeit online 2020). It remains however unclear just what effects the Covid-19 pandemic has had and still has on the movement's form of protest, its organizational structure and mobilization. This is where the research begins. In order to conduct in-depth research on the movement, the concept and methodology of citizen science appears to be a sensible approach. Despite the recognized potential of citizen science research projects and its establishment in the field of natural science, it has not yet been widely implemented in social science research. The reason for lack of its implementation and the reluctance of researchers to use this method lies in the challenge to mobilize target groups and to ensure data quality when working with non-professional researchers not to speak of researchers' ethical concerns. This research therefore helps to overcome the lacking use of citizen science in social science research and contributes to 
the discussion concerning the issues that have prevented its use in the past (Heiss/ Matthes 2017; Riesch/Potter 2014).

\section{Research Design and the Role of Citizen Science}

The project has been designed before the pandemic outbreak. Regardless of the manifold impact of Covid-19 on the way the project has been conducted ever since (see below), it has been based on Irwin's (1995) understanding of the mutually beneficial relationship between citizens and science. On the one hand, science is supposed to be responsive to citizens' concerns and needs while on the other, citizens are capable of producing academic knowledge. The project addresses both dimensions in a win-win scenario. As to the former, FFF activists show interest in getting to know more about the movement's members, motivation, narratives and functional modalities (Brünker/Deitelhoff/Mirbabaie 2019; de Moor et al. 2020). As to the latter, young FFF activists based in Düsseldorf are co-researchers of the project. The rationale of bringing experienced researchers and young activists together is not only to "[attract] more scientists into public engagement work" (Bauer/Jensen 2011) but also to produce a specific kind of knowledge based on a comprehensive access to the empirical field on the ground. In other words, by getting the core FFF activists on board the scientific process will benefit from their eyes, ears and minds. More in-depth micro analyses seem thus more feasible than traditional desk studies. The activists not only benefit from deeper insights into their own movement. They also get trained in social science methods. Acquiring theoretical and methodological skills is worthwhile as they prepare the activists for their own (academic) careers. Besides compensating the co-researchers with allowances per workshop attendance, they also receive a certificate of participation at the end of the project which the activists can refer to in their CVs.

This article presents findings of a national survey designed in cooperation with FFF activists on how the movement responded to the manifold challenges posed by Covid-19. The dual experiences of collaboratively designing that survey while ethnographically analyzing the process will be discussed further below (see below). Generally, the Citizen Science (CS) project has been based on two overarching research interests: First, how does the movement in Düsseldorf work in terms of communication, organization and mobilization? Second, what kind of lessons can be learned from the local experiences in terms of political participation in general? In order to address these issues, the project makes use of a fourfold research approach (see table 1): CS workshops; mixed method research; public relations; publishing. (A) The major CS interaction between the experienced scholars and the ten FFF activists happens in five rounds of one day workshops over a total time span of ten months. Corresponding to the traditional social science approach of starting with the research question design and ending with the interpretation of 
empirical findings, each workshop focuses on one phase of the different research steps (Diekmann 2017). Each workshop is divided into theoretical inputs by the scholars and interactive activities allowing the young participants to contribute their comments, ideas and queries as part of the process. This layout has proved fruitful as the activists thus delve into their roles as co-producers of knowledge. The more ownership they get, the more commitment and trust is established which in turn impacts positively on the research process. The mix of theoretical input on the one hand and interaction on the other is important because most of the coresearchers are either in their first university year or still enrolled at high school. (B) During workshops the merits and limitations of both qualitative and quantitative research designs are reflected upon on the basis of academic literature. In the course of the collaborative work, the experienced scholars and the co-researchers have identified four major tools to approach the research questions: online surveys (as presented in this article), focus groups, expert interviews and participant observation of local group meetings. The major advantage of choosing these instruments is the access to the field provided by the activists. (C) While the workshops and the scientific output produce a rather closed shop system between the experienced scholars and the co-researchers, public relations are yet another important pillar of the project. Public awareness is raised by two means. First, the workshop results and preliminary findings such as provided by the online survey are published at the project blog. Second, in the final stage of the project a BarCamp event will be organized to bring together the CS project team on the one hand and the interested public on the other. At best, a variety of actors from different segments of society will participate and share their perspectives on how to make use of the findings in terms of generally increasing political participation. (D) The CS and FFF related experiences will be published in the aftermath of the project.

Table 1: Project methodology

\begin{tabular}{|l|l|l|l|l|}
\hline $\begin{array}{l}\text { research } \\
\text { interests }\end{array}$ & \multicolumn{3}{|l|}{ research approach } \\
\hline A: CS workshops & $\begin{array}{l}\text { B: mixed } \\
\text { methods }\end{array}$ & $\begin{array}{l}\text { C: public rela- } \\
\text { tions }\end{array}$ & D: publishing \\
\hline $\begin{array}{l}\text { mobilization and } \\
\text { organization of } \\
\text { FFF }\end{array}$ & $\begin{array}{l}\text { conceptual } \\
\text { work, theoreti- } \\
\text { cal inputs, inter- } \\
\text { active contri- } \\
\text { bution }\end{array}$ & $\begin{array}{l}\text { online surveys, } \\
\text { focus groups, } \\
\text { expert inter- } \\
\text { views, parti- } \\
\text { cipant obser- } \\
\text { vation of local } \\
\text { political partici- } \\
\text { pation }\end{array}$ & $\begin{array}{l}\text { blog, YouTube, } \\
\text { locial media, } \\
\text { local newspa- } \\
\text { pers, BarCamp }\end{array}$ & $\begin{array}{l}\text { conferences, } \\
\text { newspaper } \\
\text { pieces, acade- } \\
\text { mic journals }\end{array}$ \\
\hline
\end{tabular}

Source: own illustration based on project outline

The ownership rationale of the CS approach can be a double-edged sword. On the one hand, the integration of FFF activists allows for better access to the field. On the other hand, the lack of academic experience on behalf of the co-researchers or 
unorthodox ways of approaching research might cause frictions or delays throughout the process. In sum however, getting the core activists on board has enriched the research activities. For instance, it has been the co-researchers' idea to focus on the internal decision-making processes of the FFF movement. Ever since, the project focuses on the internal hierarchies and positions of certain stakeholders on different organizational levels. Apparently, the co-researchers are interested in better understanding why some decisions are taken while others are not. Their motivation to focus on decision-making processes is based on their reflection on the sometimes non-transparent decision dynamics within the movement. According to the official principles of FFF in Germany the movement is based on "grassroots democratic" principles (Fridays For Future Germany 2020: 1). However, preliminary research results indicate strong hierarchies within the movement. One activist commented: "The federal level consists of particularly active activists and, over time, they naturally develop institutional power". These hierarchies are not limited to institutional power in the form of working groups or other decision-making bodies such as the "Deli-Konferenz" (conference of the delegates of the local groups). Some leaders have been described as particularly influential. Actors of FFF who are present in the media seem to be able to internally use their public presence for their agenda. One activist commented: "Every time Luisa [Neubauer; one of the most famous characters of FFF in Germany] makes a proposal for action, it actually always gets through. Naturally, this may lead to frictions among members". Certain people in the movement have prestige and/or are rhetorically strong, she added.

This example does not only illustrate the project team's CS commitment to make the co-researchers "tell a story about the people or group that is the focus of their research" (LeCompte/Schensul 1999: 2). Moreover, it demonstrates the ethnographic character of the project. The co-researchers are not only the subjects of analysis by cooperating with the experienced scholars in the different phases of the project. They are also the objects of analysis as their scientific contribution is being constantly observed by the experienced scholars. Their dual function or rather contribution is communicated in a transparent manner throughout the entire analysis process. Against the backdrop of participant observation, this ethnographic research is understood as the examination of the behavior of the citizen scientists in the special CS social situation and understanding the group members' own interpretation of their behavior and interpretations in their local contexts (GraceMcCaskey et al. 2019: 4).

The setting up of the online survey on the effects of Covid-19 on FFF is yet another example that illustrates this relationship. Other than a general interest in the impact of the pandemic on the movement, there had been no specific set of items prepared when scholars and activists first came together to develop the survey. There has merely been mutual interest on both sides into the resilience of the 
movement. Both scholars and co-researchers wondered about the coping capacities of FFF as an organization facing the pandemic. The concept of resilience was defined as the ability of a movement to cope with external stress and disturbances as a result of social, political, or environmental change (Adger 2000:347). The designing of the survey followed a twofold CS approach. On the one hand, the coresearchers autonomously steered the identification of relevant questions and specific items in the survey (see below). On the other hand, the experienced scholars analyzed this process of civic engagement from a participatory observation perspective. Given the lack of experience, the analysis of the survey results as well as the publication efforts have been in the hands of the scholars. It remains to be seen how to better integrate the co-researchers into the latter activities in the future. A full-fledged cooperation in all aspects of the academic work is not ruled out per se as the project is generally based on a dynamic understanding of collaboration.

Research interests and methodologies are decided upon in a cooperative and nonhierarchical manner. This open-mindedness has helped to properly adapt to the Covid-19 situation. For instance, the first workshops have been held via videoconferences. The preliminary results were discussed in an asynchronous manner on virtual platforms such as padlet or google docs. The dynamic CS character of the project does not only allow for content-related and technological adaptations to the pandemic situation. Moreover, the project is supposed to be adaptable to other CS approaches addressing different societal actors in an integrative manner. Regarding the impact of the pandemic on the project, there have been both benefits and pitfalls. On the one hand, instead of meeting up in person every other two months, all workshops have been held via video conferences. This allowed activists to participate without having to physically travel to the workshop location. The co-researchers were thus able to take part in the process from wherever they might have been based at that particular moment. However, the lack of direct non-virtual exchange made it more difficult to get to know each other on a more personal level. Given the duration of almost one year collaborating with each other, it is likely that mutual trust and commitment could have been even more profound if the experienced scholars and the activists had spent workshop days together in a physical instead of virtual room - coffee break chats included. Yet another pitfall has been the cancellation of the public kick-off event at the very beginning of the project, which was originally planned as a BarCamp open to the citizens of Düsseldorf and beyond. There have been no repercussions on the actual research process. The kick-off event however would have been a great opportunity to become better acquainted and a chance to work intensively together on the preparation of the event as well as to offer the possibility to resolve hierarchy obstacles. Unfortunately, this trust building process could not take place. Furthermore, it is likely that the CS project became less visible in local media because of the cancellation of the public kick-off event. As a response the project team increased its publicity efforts at the project blog website. 


\section{Survey on FFF during Covid-19}

In response to the Covid-19 pandemic, an online survey was designed and sent to all local FFF groups throughout Germany. This allowed for continuation of the CS project despite the various restrictions and delays (e.g. social distancing). Also, the co-researchers were able to get involved and thus learned that research projects constantly have to adapt to external factors. In terms of the research agenda, the pandemic served as a starting point for analysis as many observers expected FFF to adapt their mobilization practices to the new circumstances. Against this backdrop, the research focused on the movement's actions to better understand changes, influencing factors and adjustments under these conditions. The leading question of this online survey therefore was: What effects does the Covid-19 pandemic have on the way FFF works? In contrast to previous studies (Koos/Naumann 2019; Sommer et al. 2019), the CS rationale was to gain insight into the internal structures of the movement by questioning the core activists and not only the people protesting at major events.

The first draft of the online questionnaire was developed by a core team of experienced researchers and then released to the co-researchers through an online collaboration tool for further editing (i.e. google doc, padlet). This collaboration process proved fruitful as the young activists added and/or discarded aspects that had largely been overlooked in the first draft. For instance, placard and chalk protest forms or the "App for Future" were specific items none of the experienced scholars had thought of as particularly relevant. The final version of the questionnaire was then set up as an online questionnaire and distributed by the co-researchers via the movement's networks. The questionnaire was exclusively placed in internal channels for communication and organization. One of the CS challenges was the call for activists to participate in the survey. Usually, it is difficult for researchers to enter internal FFF messenger groups, as they only admit activists of their own movement. Some activists replied to the researchers' messages that they principally do not forward messages. Others, however, were willing to spread the survey link. The co-researchers of the Düsseldorf FFF group passed the survey on to exclusive groups and were able to give information concerning the project when asked. Presumably, these connections into the movement itself strengthened the credibility and relevance of the survey. This was all the more necessary as, according to the co-researchers, a large number of survey queries are regularly sent to (public) FFF WhatsApp groups. The online questionnaire addressed two major dimensions: (1) the importance of the channels used for communication, organization and mobilization prior and since the outbreak of the pandemic in Germany, (2) the participation in certain actions prior and since the outbreak of the pandemic in Germany. The questions dealt with the respondent's perception of the respective local group and aimed at revealing differences between offline and online 
activities. The online survey contained 13 questions and was conducted from May to June 2020. SPSS was used to quantitatively analyze the online questionnaire. The focus was on descriptive statistics, as a bivariate evaluation was limited due to the small sample size $(n=103)$.

The results of the online survey are in line with prominent national youth studies (Hurrelmann et al. 2019), first (international) findings on the FFF movement (Koos/Naumann 2019; de Moor et al. 20) as well as findings on youth media use research (mpfs 2019). However, the present analysis reveals a number of special characteristics that have not been presented in this way on the basis of current data. For instance, the results differentiate between the public FFF protesters and the committed activists within the social movement. In contrast to prominent studies such as those by Sommer et al. (2019) or de Moor et al. (2020), the online survey has been completed by core activists only. The survey has not been distributed at Fridays demonstrations where the distinction cannot be made between active and less engaged activists.

\subsection{Distribution of gender and age}

The gender distribution in the sample is similar to that in previous studies on the German FFF movement at demonstrations (Sommer et al. 2019; Koos/Lauth 2019): 56 percent of the respondents are women, 40 percent men and four percent diverse. The findings support the assumption of a movement being dominated by female activists. In terms of age structure, there are relevant differences between the surveys conducted at demonstrations and this survey of activists in the organization of the movement. 80 percent in this dataset are under 20 years of age, almost half of the respondents are younger than 18 . This article thus provides evidence that those directly involved in the organization of FFF are much younger than the participants of the demonstrations, as the mean age was 34 in September 2019. Although the social base of FFF in Germany expanded to older cohorts over the course of 2019, the active core in the local groups does not seem to be heavily affected (Koos/Lauth 2019; Neuber/Gardner 2020).

\subsection{Messenger - a catch-them-all tool, social media fades into the background}

The huge importance of messenger services is obvious when looking at the channels that FFF activists use both for internal communication and organization as well as for mobilizing their supporters. Regardless of whether asked about the most important means of communication prior or since the Covid-19 crisis, almost all respondents state that these are the most important channels. For internal communication and organization, more than 90 percent of activists rate the messenger services as either "important" or "very important" (see figure 1). With regard to the use of these tools for mobilization before the Covid-19 crisis, more than 
90 percent of respondents also considered them relevant, although there has been a slight decline to 85 percent since the start of the pandemic (see figure 2).

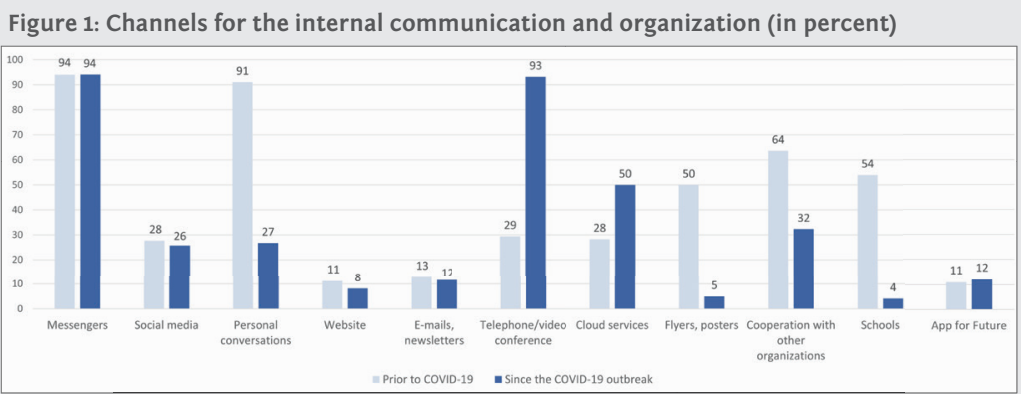

Percent of respondents who answered that these channels were "important" or "very important" for the internal communication and organization. The question wording was: "How important were the following channels for the internal communication and organization of your local group prior to/since the Covid-19 outbreak?"2 $n=103$

Source: own illustration based on online survey

The findings show that WhatsApp and Telegram have become all-embracing tools of the movement. Through openly accessible channels on these platforms, activists keep each other, and their supporters informed about planned actions or new information. The JIM Study 2019 already showed that messenger services have outrun social media platforms and WhatsApp has become the most important app among young people (mpfs 2019). The situation is different with the use of social media by young people. While the JIM Study 2019 shows that Instagram, Snapchat and Co. play a significant role for young people in all life contexts (mpfs 2019), young activists seem to have a benefit orientation in mind here. Social networks, for example, have a consistently high priority in mobilization (see figure 2). Before the pandemic, 90 percent of the respondents rated them as important. Since the outbreak of Covid19 , the figure has risen to 95 percent. However, the same social media tools seem to play a lesser role in communication and organization among themselves (see figure 1) - even with a slight downward trend (from $28 \%$ to $26 \%$ ). Another interesting finding is the increased use of cloud services from 28 percent to 50 percent (see figure 1). This data shows that FFF was able to access previously used digital infrastructure after the outbreak of the pandemic and then intensified its use.

2 In Germany, the freedom of assembly was restricted in March 2020. 
Figure 2: Communication channels for mobilization (in percent)

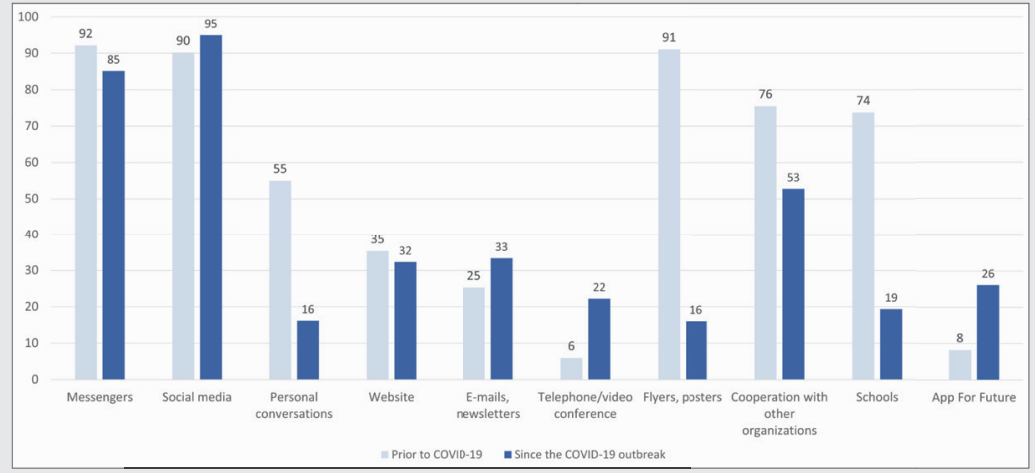

Percent of respondents who answered that these channels were "important" or "very important" for mobilization. The question wording was: "How important were the following channels for mobilization prior to/since the Covid-19 outbreak?"

$n=103$

Source: own illustration based on online survey

\subsection{Personal communication is shifting to digital space}

It does not come as a surprise that the movement resorted to videoconferencing during the Covid-19 pandemic - especially for internal communication and organization. The striking finding here, however, is the fact that an unusual tool is used for this purpose. With Discord, some of the local groups have lent themselves a communication tool from the online gaming scene. For example, the young activists state that they consider videoconferencing tools such as Zoom and Discord to be important for mobilization since the outbreak of Covid-19 with 22 percent. With regard to internal collaboration, the rate was already 29 percent before Covid-19 and has risen to 93 percent since (see figure 1). The "App for Future" became one substitute channel for the mobilization during the pandemic as the German version of the app was first released in May 2020 and was increasingly used during the times of the pandemic (see figure 2). The sharp decline in personal communication is yet another important finding. While before the pandemic 91 percent of those surveyed considered this communication channel to be important for internal processes, this figure has dropped to only 27 percent since the crisis (see figure 1). There was also a drop in the personal communication for mobilization, from 55 percent to 16 percent (see figure 2). At first glance, this finding seems obvious as all communication worldwide has shifted to digital since the pandemic. However, major studies on the movement show without exception how important personal contact is for mobilization within FFF. Sommer et al. (2019), for example, show that for more than 90 percent of the young people demonstrating in September 2019, personal conversations with friends and family play the most important 
role as a source of information. Social media (62\%), television and radio (50 \%) or advertising flyers (30 \%) follow. The strong bond with friends and classmates is also evident in terms of accompanying persons during demonstrations. From this finding, it can on the one hand be assumed that with the loss of this communication channel, a very important factor is absent to keep the movement going. On the other hand, though, it is a remarkable achievement and a proof for resilience of the movement since the activists more and more managed to shift their communicative focus to alternative (digital) channels to retain public attention. It remains to be seen what the long-term effects of missing personal communication might hold for the sustenance and future dynamic of the movement.

\subsection{Digital organization, digital communication - digital protest?}

Regarding the impact of the pandemic on the forms of protest, the major finding is similar to the results on organization and mobilization prior to and since the Covid19 outbreak. Although the street protests on Fridays shaped public perception of FFF, it has essentially been a digitally operating movement already prior to the pandemic. Important aspects of communication, organization, mobilization and protest actions happened online before the global pandemic. This also explains the movement's resilience against the impact of Covid-19. More than 36 percent of the respondents state that their local group was frequently or very frequently involved in "social media actions" before the outbreak of Covid-19 in Germany and more than 15 percent were involved in so-called online climate strikes. One fifth stated that their local groups participated in "online meetings and assemblies". Since the outbreak of the pandemic, these figures have risen substantially. Two thirds of respondents say that their local group takes part in a digital strike on a regular basis, 56 percent in social media actions, 65 percent in online meetings and assemblies and 47 percent in webinars and online lectures. Physical protests have decreased to the same extent. With a decrease of 73 percentage points, just under eleven percent state that their local group has frequently participated in street protests since the start of the pandemic in Germany. Protest posters (from $67 \%$ to $8 \%$ ) and chalk protest ( $47 \%$ to $26 \%$ ) also declined considerably (see figure 3 ). 
Figure 3: Actions by Fridays for Future activists (in percent)

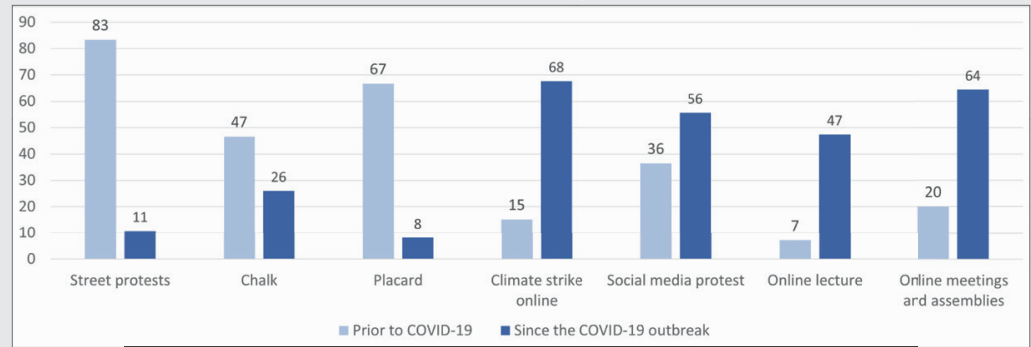

Percent of respondents who answered that these protest actions were taken "frequently" or "very frequently" by FFF activists. The question wording was: "How often has your local group participated in the following actions prior to/since the Covid-19 outbreak?"

$n=103$

Source: own illustration based on online survey

In one of the workshops with the citizen scientists the data from the survey was presented. Three of the co-researchers' reactions seem most relevant with regard to the pandemic impact on FFF: First, the citizen scientists confirm the significance of messengers for internal communication. Since most activists also use them privately, messengers are considered "the simplest way to communicate" and have therefore been used before the pandemic to such a great extent. Second, the growing importance of cloud services during the pandemic has been due to the value of these services as a digital space for sharing e.g. protocols or pictures for social media. Third, the "App for Future" already existed in an international version before the pandemic outbreak. In terms of coping capacities from a resilience perspective, the launch of the German "App for Future" in May demonstrated the movement's ability to quickly adapt to the new circumstances.

\section{Conclusion}

The analysis shows that FFF has been strikingly resilient to the Covid-19 crisis. In line with the survey results, the collaborating citizen scientists explain the resilience with the movement's digital backbone that apparently existed before the pandemic outbreak. Three findings stand out in this regard. First, messenger services such as WhatsApp or Telegram remain the major tools to communicate, organize, and mobilize. Messenger services have been most important prior and after the pandemic outbreak while other social media remained important for the mobilization of FFF. Second, personal communication in its traditional non-digital understanding has shifted to the digital space. Social distancing and assembly restrictions have led to a substantial drop in the importance attributed by FFF members to personal communication ( $91 \%$ vs. $26 \%$ ). While the online survey and the involved CS activists argue that videoconferencing and other means compensate for the lack 
of direct exchange. However as in other realms of everyday life (e.g. home office debate), it remains to be seen what the long-term effects of missing personal communication might hold for the sustenance and future dynamic of the movement. Third, while physical means of protesting such as street protests, chalk or placard activities cease to really work since the pandemic, already previously used methods such as online strikes, online meetings, or social media campaigns have been on the rise. In sum, FFF merely adapted its pre-existing methodologies in terms of communication, organization and mobilization to the digital space without compromising its outreach and impact.

Based on the experiences of designing an online survey as an adaptation to the pandemic circumstances, the analysis also shows that making young FFF activists coproducers of academic knowledge can be fruitful in two ways. First, it is the coresearchers that provide experienced scholars with access to the empirical field that otherwise would not be likely to get by. The online questionnaire would not have reached the core activist groups if not facilitated by the co-researchers. Second, as the conceptualization and execution of the online survey has shown it is them who steer the direction of relevant research topics. This collaborative reflection process gives the knowledge output its specific CS character. Both in terms of insight and outreach of academic knowledge. Despite some limitations such as a relatively low return rate for the survey ( $\mathrm{n}=103 \mathrm{vs.} 650$ local groups), the holding of non-physical workshops only, or the lack of access to prominent activists such as Greta Thunberg or Luisa Neubauer, the project holds relevant implications for future research both on FFF and CS. Against all odds of the pandemic induced restrictions, the digital backbone of the movement demonstrates FFF's resilience as an organization.

Regarding CS approaches, bringing citizen science and scholars together makes sense for all parties involved. On the one hand, from the experienced scholars' perspective the benefits of access, knowledge gain, and outreach outweigh the costs of conducting a CS project. On the other hand, the activists' gains are largely in acquiring theoretical and methodological skills in conducting research projects that might not only come in handy in their CVs but also in future (academic) careers. Besides these and other benefits, CS costs involve organizational, communicational and other issues CS aspirants need to consider in every step of the process. For instance, the citizen scientists' dropout rate needs to be held low in order to make a research team workable over a time period of ten months. In this project this has been achieved by making allowances to the CS activists to participate in synchronous workshops and asynchronously collaborate in the design of the online survey and other shared outputs. Yet another issue is of bureaucratic nature. Not only the Covid-19 pandemic has brought about challenges for this project by delaying the start of the co-creation phase and preventing the researchers and co-researchers from coming together in offline workshops but also the implementation of citizen science itself. 
Especially issues concerning data protection have slowed down the process of online co-creation. Due to German and European data protection regulations online conference tools such as Zoom, Discord etc. or instant messenger services such as WhatsApp, Telegram etc., which would facilitate communication between all project participants, cannot be used if data protection is taken seriously, as the security of the data cannot be guaranteed. Alternative tools provided by the University often lack a variety of functions and are usually less intuitive. Yet another data protection issue is the consent form citizen scientists need to sign before a cooperation can begin. Given the young age of some of the co-researchers this process can be longer than initially expected. Notwithstanding these issues, the article demonstrates that CS projects hold huge potential for producing specific in-depth knowledge that is difficult to acquire in traditional research settings. Also, CS projects are capable of withstanding organizational, logistical and communicational challenges such as the ones caused by Covid-19 without having to compromise on the exchange with citizen scientists and the collaborative production of academic knowledge.

\section{Bibliography}

Adger, W. Neil (2000): Social and ecological resilience: are they related?, in: Progress in Human Geography, vol. 24, no. 3, pp. 347-364.

Anzlinger, Jana und Philipp Bovermann (2019): „Wir müssen unserem Protest andere Formen geben“, in: Süddeutsche Zeitung, www.sueddeutsche.de/politik/fridays-for-future-klimastreik-aktionstag-bewegung-1.4703586 (05.08.2020).

Bauer, Martin W. and Pablo Jensen (2011): The mobilization of scientists for public engagement, in: Public Understanding of Science, vol. 20, no. 1, pp. 3-11.

Boulianne, Shelley, Mireille Lalancette and David Ilkiw (2020): "School Strike 4 Climate": Social Media and the International Youth Protest on Climate Change, in: Media and Communication, vol. 8, no. 2, pp. 208-218.

Brünker, Felix, Fabian Deitelhoff and Milad Mirbabaie (2019): Collective Identity Formation on Instagram - Investigating the Social Movement Fridays for Future, Australasian Conference on Information Systems, https://arxiv.org/ftp/arxiv/papers/1912/1912.05123.pdf (10.08.2020).

Diekmann, Andreas (2017): Empirische Sozialforschung. Grundlagen, Methoden, Anwendungen, 11. Aufl., Reinbek.

Fridays For Future Germany (2020): Strukturpapier, https://cloud.fridaysforfuture.is/s/ fEigF5kozP4oEXD\#pdfviewer (10.08.2020).

Grace-McCaskey, Cynthia A., Briana latarola, Alex K. Manda and J. Randall Etheridge (2019): EcoEthnography and Citizen Science: Lessons from Within, in: Society \& Natural Resources, vol. 32, no. 10, pp. 1123-1138.

Heiss, Raffael and Jörg Matthes (2017): Citizen Science in the Social Sciences: A Call for More Evidence, in: GAIA - Ecological Perspectives on Science and Society, vol. 26, no. 1, pp. 22-26.

Hurrelmann, Klaus, Gudrun Quenzel, Ulrich Schneekloth, Ingo Leven, Mathias Albert, Hilde Utzmann und Sabine Wolfert (2019): Jugend 2019, 18. Shell-Jugendstudie, Weinheim.

Irwin, Alan (1995): Citizen Science: A study of people, exercise and sustainable development, New York. 
Koos, Sebastian und Elias Naumann (2019): Vom Klimastreik zur Klimapolitik: Die gesellschaftliche Unterstützung der Fridays for Future-Bewegung und ihrer Ziele, http://kops.uni-konstanz. de/bitstream/handle/123456789/46901/Koos_2-1jdetkrk6b9yl4.pdf?sequence=1\&isAllowed=y (10.08.2020).

Koos, Sebastian und Franziska Lauth (2019): Die Entwicklung und Zukunft der Fridays for Future-Bewegung, Forschungsbericht, https://kops.uni-konstanz.de/handle/123456789/47196 (28.08.2020).

LeCompte, Margaret D. and Jean Schensul (1999): Analyzing \& Interpreting ethnographic data, Walnut Creek.

de Moor, Joost, Katrin Uba, Mattias Wahlström, Magnus Wennerhag and Michiel De Vydt (eds.) (2020): Protest for a future II: Composition, mobilization and motives of the participants in Fridays For Future climate protests on 20-27 September, 2019 in 19 cities around the world, www.researchgate.net/publication/339443851_Protest_for_a_future_II_Composition_mobilization_and_motives_of_the_participants_in_Fridays_For_Future_climate_protests_on_2027_September_2019_in_19_cities_around_the_world/link/5e53000e458515072db797c4/download (05.08.2020).

mpfs - Medienpädagogischer Forschungsverbund Südwest (2019): JIM-Studie 2019. Jugend, Information, Medien, www.mpfs.de/studien/jim-studie/2019/ (10.08.2020).

Neuber, Michael and Beth G. Gardner (2020): Germany, in: Protest for a future II: Composition, mobilization and motives of the participants in Fridays For Future climate protests on 20-27 September, 2019 in 19 cities around the world, ed. by Joost de Moor, Katrin Uba, Mattias Wahlström, Magnus Wennerhag and Michiel De Vydt, pp. 117-138, www.researchgate.net/ publication/339443851_Protest_for_a_future_II_Composition_mobilization_and_motives_of_ the_participants_in_Fridays_For_Future_climate_protests_on_20-27_September_2019_in_19_ cities_around_the_world/link/5e53000e458515072db797c4/download (05.08.2020).

della Porta, Donatella and Mario Diani (1999): Social Movements. An Introduction, Oxford.

Riesch, Hauke and Clive Potter (2014): Citizen science as seen by scientists: Methodological, epistemological and ethical dimensions, in: Public Understanding of Science, vol. 23, no. 1, pp. 107-120.

Rucht, Dieter (2019): Faszinosum Fridays for Future, in: Aus Politik und Zeitgeschichte, 69. Jg., Heft 47/48, S. 4-9.

Sommer, Moritz, Dieter Rucht, Sebastian Haunss und Sabrina Zajak (2019): Fridays for Future. Profil, Entstehung und Perspektiven der Protestbewegung in Deutschland, Institut für Protest- und Bewegungsforchung, Working Paper 2, Berlin.

Süddeutsche Zeitung (2020a): Fridays for Future startet Netzstreik, www.sueddeutsche.de/politik/demonstrationen-neuruppin-fridays-for-future-startet-netzstreik-dpa.urn-newsml-dpacom-20090101-200424-99-816175 (05.08.2020).

Süddeutsche Zeitung (2020b): Plakate statt Menschen: Fridays for Future mit Kunstprotest, www.sueddeutsche.de/politik/demonstrationen-berlin-plakate-statt-menschen-fridays-forfuture-mit-kunstprotest-dpa.urn-newsml-dpa-com-20090101-200424-99-821679 (05.08.2020).

Wahlström, Mattias, Piotr Kocyba, Michiel de Vydt and Joost de Moor (eds.) (2019): Protest for a future: Composition, mobilization and motives of the participants in Fridays For Future climate protests on 15 March, 2019 in 13 European cities, https:/protestinstitut.eu/wp-content/ uploads/2019/07/20190709_Protest-for-a-future_GCS-Descriptive-Report.pdf (05.08. 2020).

Zeit online (2020): Trotz Corona: Fridays for Future will wieder weltweit auf die Straße, www. zeit.de/news/2020-07/24/fridays-for-future-will-wieder-weltweit-auf-die-strasse (06.08.2020). 